\title{
Europium (II)-Doped Microporous Zeolite Derivatives with Enhanced Photoluminescence by Isolating Active Luminescence Centers
}

\author{
Xuyong Yang, ${ }^{+}$Tan Swee Tiam, ${ }^{\dagger}$ Xibin Yu, ${ }^{*, \neq}$ Hilmi Volkan Demir, ${ }^{*,+\S, \perp}$ and Xiao Wei Sun ${ }^{*,+, \#}$ \\ ${ }^{\dagger}$ School of Electrical and Electronic Engineering and ${ }^{\S}$ School of Physical and Mathematical Sciences, Nanyang Technological University, \\ Nanyang Avenue, Singapore 639798 \\ ${ }^{\ddagger}$ Department of Chemistry, Shanghai Normal University, Shanghai 200234, P. R. China \\ ${ }^{\perp}$ Department of Electrical and Electronics Engineering, Department of Physics, UNAM-Institute of Materials Science and \\ Nanotechnology, Bilkent University, Bilkent, Ankara, Turkey 06800 \\ "Department of Applied Physics, College of Science, and Tianjin Key Laboratory of Low-Dimensional Functional Material Physics and \\ Fabrication Technology, Tianjin University, Tianjin 300072, China
}

Supporting Information

ABSTRACT: Solid-state reaction is the most common method for preparing luminescent materials. However, the luminescent dopants in the hosts tend to aggregate in the high-temperature annealing process, which causes adverse effect in photoluminescence. Herein, we report a novel europium (II)-doped zeolite derivative prepared by a combined ion-exchange and solid-state reaction method, in which the europium (II) ions are isolated to a large extent by the micropores of the zeolite. Excited by a broad ultraviolet band from 250 to $420 \mathrm{~nm}$, a strong blue emission peaking at $450 \mathrm{~nm}$ was observed for these Euembedded zeolites annealed at $800{ }^{\circ} \mathrm{C}$ in a reducing atmosphere. The zeolite host with pores of molecular dimension was
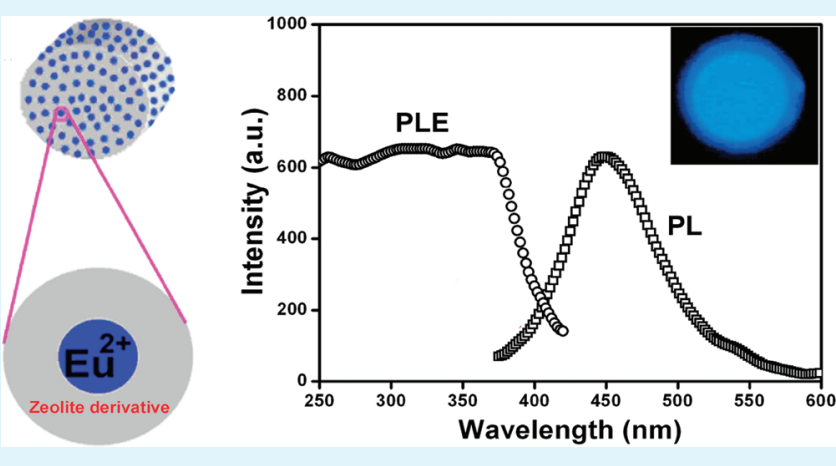
found to be an excellent host to isolate and stabilize the $\mathrm{Eu}^{2+}$ ions. The as-obtained europium (II)-doped zeolite derivative showed an approximately 9 fold enhancement in blue emission compared to that of the general europium (II)-doped aluminosilicates obtained by conventional solid-state reaction, indicating that, by isolating active luminescence centers, it is promising to achieve highly luminescent materials. Also, the strong blue emission with broad UV excitation band suggests a potential candidate of phosphor for ultraviolet excited light-emitting diode.

KEYWORDS: zeolite, ion-exchange, solid-state reaction, photoluminescence, luminophor, LED

\section{INTRODUCTION}

Luminescent materials doped with isolated active luminescence centers are important for applications in numerous fields including displays, lighting, and optical telecommunications for their enhanced emission property thanks to the reduction of concentration quenching effects in such material systems. ${ }^{1-6} \mathrm{On}$ the other hand, the solid-state reaction method is the most common method for preparing luminescent materials with high crystallinity. ${ }^{7,8}$ However, the luminescent dopants tend to aggregate in the high-temperature annealing process. Microporous and nanoporous material systems with special featuring pore structures have been regarded as potential hosts for isolating active centers in the resulting system. Qiu et al. reported an isolated bismuth-doped nanoporous glass prepared by soaking the nanoporous glass in Bicontaining solutions and then treating the glass with postannealing. ${ }^{9}$ Aluminosilicate systems have also been regarded as excellent luminescence hosts with stable crystal structure and high thermal stability. Many investigations on phosphors with aluminosilicate as a host material have also been reported in the past. ${ }^{7,8,10-15}$ Among them, zeolites are special form of crystalline aluminosilicates with pores of molecular dimension. As a result, functionalized zeolites and their derivatives have been emerged as a new class of luminophor hosts in recent years. ${ }^{16-27}$

Currently, the phosphor-converted white light-emitting diode (PC-WLED) is the most promising technology for solid-state lighting. ${ }^{28-31}$ To date, there are two schemes in PC-WLED. One is the combination of a blue LED with yellow phosphor (YAG: $\mathrm{Ce}^{3+}$ ) by blending the blue from the LED and yellow from the phosphor resulting in white. However, the disadvantage of the white LEDs is the white light emission is rather "cold", which is not suitable in the applications where "warm" light is generally required. ${ }^{32}$ Another approach of obtaining white light is to combine a near-UV LED (around $370-410 \mathrm{~nm}$ ) with red, green and blue (RGB) emitting phosphors. ${ }^{33-37}$ This approach could

\section{Received: August 16, 2011}

Accepted: October 21, 2011

Published: October 21, 2011 


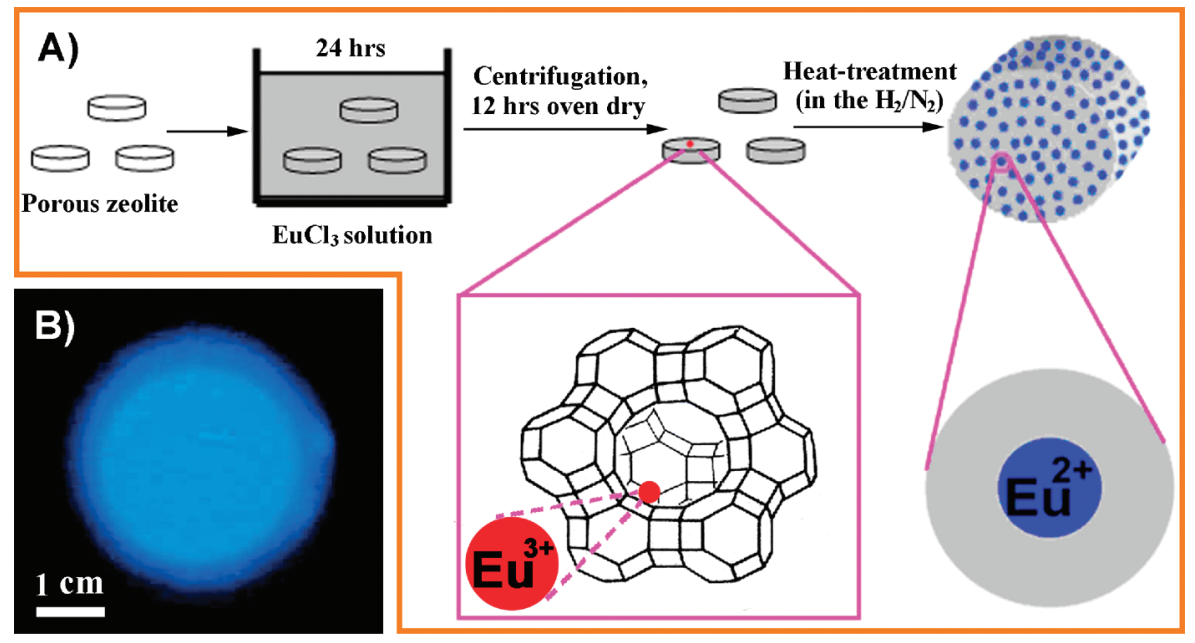

Figure 1. (A) Schematic of the fabrication procedure of the europium (II)-doped zeolite derivatives. (B) Photograph of a europium (II)-doped zeolite derivative sample excited by UV light.

yield a white LED very high photometric performance, provided the RGB emitting phosphors are optimized. To increase the efficiency of the white LEDs, special attention has recently been paid to the development of novel RGB phosphors that can absorb in the near-UV range efficiently. Rare earth europium (II)-activated phosphors have been widely used in energy-saving fluorescent lamps and light emitting diodes ${ }^{38-40}$ because of the efficient $4 \mathrm{f}-5 \mathrm{~d}$ transition of $\mathrm{Eu}$ (II) ions and the possibility to tune their excitation and emission wavelength. Recently, luminescence from rare-earth-functionalized zeolites has been studied, promising for applications as phosphors, lasers and NIR emitters. ${ }^{21-27}$ However, the $\mathrm{Eu}^{2+}$-activated zeolites or zeolite derivatives have been relatively less reported, and there are lots of disadvantages in the current systems such as low luminescence efficiency and existence of $\mathrm{Eu}^{3+41}$ or lack of visible light emission. ${ }^{42}$ Among previous studies, many works focused on the study of trivalent $\mathrm{Eu}^{3+}, \mathrm{Tb}^{3+}, \mathrm{Nd}^{3+}$, and $\mathrm{Er}^{3+}$-activated zeolites to produce red, green, or near-infrared emission and none of them presents an effective approach to yield strong visible emission from pure $\mathrm{Eu}^{2+}$-activated zeolites, primarily because the $\mathrm{Eu}^{2+}$-incorporated zeolites are difficult to obtain directly by ion exchange method as a result of the instability of $\mathrm{Eu}^{2+}$ in aqueous solution and the large difference in the radius of $\mathrm{Eu}^{2+}$ and the exchanged ions of zeolites.

In this paper, we report a europium (II)-doped zeolite derivative with strong blue emission by an ion-exchange process and subsequent high-temperature annealing in $\mathrm{H}_{2} / \mathrm{N}_{2}$ atmosphere. Much stronger blue emission is obtained as compared to the conventional solid-state reaction method. The results indicate that the micropores of zeolites act as a spacer to successfully isolate $\mathrm{Eu}^{2+}$ ions and prevent them from aggregation. These micropores of zeolite 13X not only play a key role in isolating the active centers, but also serve as host for stabilizing the active centers.

\section{EXPERIMENTAL SECTION}

Synthesis of Europium (II)-Doped Zeolite Derivatives. All chemicals were purchased from commercial sources (analytical grade) and used without further purification. The $\mathrm{Na}$ type faujasite type-zeolite $13 \mathrm{X}\left(\mathrm{Na}_{2} \mathrm{O} \cdot \mathrm{Al}_{2} \mathrm{O}_{3} \cdot(2.8 \pm 0.2) \mathrm{SiO}_{2} \cdot(6-7) \mathrm{H}_{2} \mathrm{O}\right)$ was supplied by Shanghai Tongxing Molecular Sieve Co., Ltd. First, $\mathrm{Eu}_{2} \mathrm{O}_{3}$ was dissolved by $\mathrm{HCl}(36 \%-38 \%$, analytical grade $)$ and diluted by the distilled water into $0.1 \mathrm{~mol} / \mathrm{L} \mathrm{EuCl}_{3}$ solution. Then $\mathrm{Na}$ type zeolite $13 \mathrm{X}(4.5 \mathrm{~g})$ was immersed in the $\mathrm{EuCl}_{3}$ solution $(30 \mathrm{~mL})$. The solution was stirred at $80^{\circ} \mathrm{C}$ for $24 \mathrm{~h}$. Afterward the ion-exchanged zeolites were collected by the centrifugation and washed with the deionized water to remove the excess $\mathrm{Eu}$ ions and $\mathrm{Na}$ ions. The final isolated $\mathrm{Eu}^{2+}$-doped zeolite derivatives were obtained by annealing the Eu-incorporated zeolites at $800{ }^{\circ} \mathrm{C}$ for $3 \mathrm{~h}$ in a reducing ambient $\left(5 \% \mathrm{H}_{2}+95 \% \mathrm{~N}_{2}\right)$.

Characterization. The structures of as-prepared products were characterized by powder X-ray diffraction (XRD) (Rigaku DMAX 2000 diffractometer equipped with $\mathrm{Cu} / \mathrm{K} \alpha 1$ radiation, $\lambda=1.5405 \AA)(40 \mathrm{kV}$, $40 \mathrm{~mA}$ ) and transmission electron microscopy (TEM, JEOL JEM2100). The photoluminescence (PL) spectrum was measured at room temperature with a VARIAN Cary-Eclipse 500 spectrofluorometer equipped with a $60 \mathrm{~W}$ xenon lamp under a working voltage of $420 \mathrm{~V}$. The excitation and emission slits were set at $5.0 \mathrm{~nm}$. Solid fluorescence quantum yields were obtained on an USS-600 labsphere (Leadership in Reflectance Technology) integraph excited at $370 \mathrm{~nm}$. Specific surface area $\left(S_{\mathrm{BET}}\right)$ was calculated using the multiple-point Brunauer-EmmettTeller (BET) method in the relative pressure range of $P / P_{\mathrm{o}}=0.05-1.0$ by the Barrett-Joyner-Halenda (BJH) model. The absorbance spectra were obtained over a wavelength range from 250 to $500 \mathrm{~nm}$ using a UV-Vis spectrophotometer (SHIMADZU) with a 50W halogen lamp and a deuterium lamp as the excitation source. X-ray photoelectron spectroscopy (XPS) measurements were performed on a Perkin-Elmer PHI 5000C ESCA system. The zeolite $13 \mathrm{X}$ incorporated with Eu ions was characterized by thermo-gravimetric/differential thermal analyzer (TG-DTA) spectrometer (Shimadzu, DTG-60H) whose calefactive speed $(\beta)$ is $10^{\circ} \mathrm{C} / \mathrm{min}$, respectively. The content of $\mathrm{Eu}^{2+}$ in the samples was estimated by inductively coupled plasma optical emission spectrometry.

\section{RESULTS AND DISCUSSION}

The as-prepared europium (II)-doped zeolites and their derivatives were prepared by first soaking the zeolite $13 \mathrm{X}$ in $\mathrm{EuCl}_{3}$ solutions and then treating them under $\mathrm{H}_{2} / \mathrm{N}_{2}$ reducing atmosphere condition. The process is illustrated in Figure 1A. With similar size (sodium: $0.97 \AA$ and europium (III): $0.95 \AA$ ), it is possible for europium (III) to migrate into the sodalite cages and substitute the sites of sodium ions. By photoluminescence (PL) measurement, a weak emission from $\mathrm{Eu}^{3+}$ was observed (see Figure S1 in the Supporting Information), suggesting some $\mathrm{Eu}^{3+}$ was doped and activated in the zeolite $13 \mathrm{X}$ after the ion- 
exchange process. In order to achieve strong blue emission from $\mathrm{Eu}^{2+}$ ions, high-temperature annealing in $\mathrm{H}_{2} / \mathrm{N}_{2}$ atmosphere was performed. Figure $1 \mathrm{~B}$ shows an eye-visible photograph of the strong blue photoluminescence from the annealed sample excited under UV irradiation using a $365 \mathrm{~nm}$ lamp.

The X-ray diffraction (XRD) patterns of the Eu-incorporated zeolites annealed at different temperatures are shown in Figure 2. Below an annealing temperature of $800{ }^{\circ} \mathrm{C}$, the Eu-incorporated zeolites maintain their original structure, which matches well with zeolite (JCPDS card 38-0237). As the annealing temperature is further increased to $800{ }^{\circ} \mathrm{C}$, the corresponding XRD pattern shows only a very broad band peaking at around $25^{\circ}$, suggesting that the framework of zeolite $13 \mathrm{X}$ collapsed and amorphous aluminosilicate structure is formed. X-ray photoelectron spectrometer (XPS) confirmed that this zeolite derivative was composed of $\mathrm{Na}, \mathrm{Si}, \mathrm{Al}, \mathrm{O}$, and $\mathrm{Eu}$ (see the Figure S2 in the Supporting Information). However, further increasing the annealing temperature to $1000{ }^{\circ} \mathrm{C}$, the pure $\mathrm{NaAlSiO}_{4}$ phase

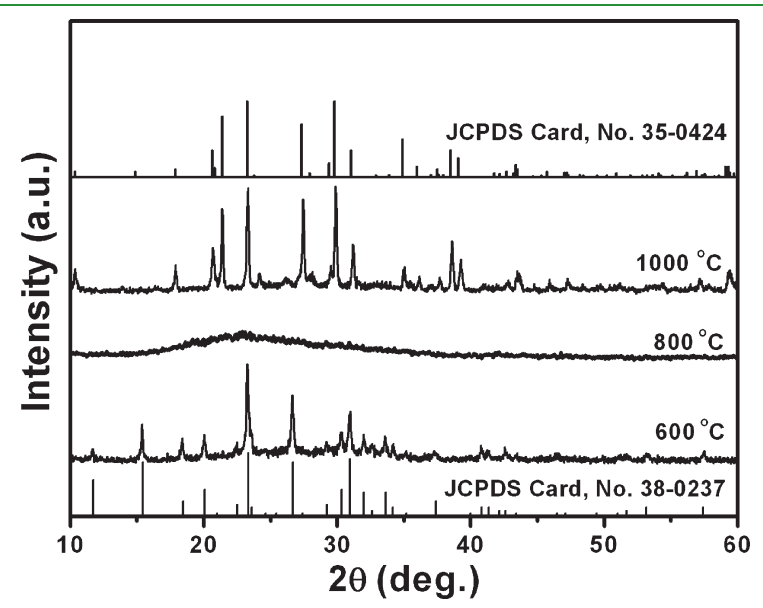

Figure 2. XRD patterns of Eu-incorporated zeolites annealed at different temperatures. gradually appears which can be clearly seen by its typical XRD pattern in Figure 2 (JCPDS Card 35-0424). The XRD analysis is in agreement with the results of thermogravimetry (TG) and differential thermal analysis (DTA). There are two exothermic peaks at around 750 and $890^{\circ} \mathrm{C}$, corresponding to the structural collapse and phase transition of zeolite ${ }^{43}$ (see Figure S3 in the Supporting Information). Transmission electron microscopy (TEM) and nitrogen adsorption isotherms were used to further confirm the phase change of Eu-incorporated zeolite sintered at $800{ }^{\circ} \mathrm{C}$. As shown in Figure 3a, the framework of the zeolite 13X is primarily a well-ordered array, dominated by regular straight parallel one-dimensional (1D) channels with a diameter of about $0.95 \mathrm{~nm}$. Figure $3 \mathrm{~b}$ depicts the TEM image of Eu-embedded zeolite annealed at $800{ }^{\circ} \mathrm{C}$ in $\mathrm{H}_{2} / \mathrm{N}_{2}$ atmosphere. It can be clearly seen that the parallel $1 \mathrm{D}$ channels are destroyed and the amorphous aluminosilicate derivative of zeolite $13 \mathrm{X}$ is formed. This agrees well with the XRD measurements. The nitrogen adsorption isotherm of the pure zeolite and zeolite derivative ( $800{ }^{\circ} \mathrm{C}$ annealed) is compared in Figure 3. A typical type-IV isotherm with sharp capillary condensation steps can be observed for pure zeolite from Figure 3c, indicating a narrow pore size distribution. However, the typical type-IV isotherms with sharp capillary condensation steps were not observed for Eu-incorporated zeolite sintered at $800{ }^{\circ} \mathrm{C}$, as shown in Figure $3 \mathrm{~d}$. The Brunauer-Emmett-Teller (BET) surface area in the pure zeolite is about $334.727 \mathrm{~m}^{2} / \mathrm{g}$, which is quite different from the normal BET surface area in Eu-incorporated zeolite derivative annealed at $800{ }^{\circ} \mathrm{C}\left(6.484 \mathrm{~m}^{2} / \mathrm{g}\right)$. The remarkable decrease of surface area in the zeolite derivative and the absence of the typical type-IV isotherm with sharp capillary condensation steps indicate that the micropore structure of zeolite $13 \mathrm{X}$ is completely collapsed with an annealing temperature of $800{ }^{\circ} \mathrm{C}$.

Interestingly, unlike general rare-earth-ion-doped compounds prepared by conventional solid-state reaction method, the $\mathrm{Eu}^{2+}$ ions are isolated in the zeolite derivatives via the ion-exchange and solid-state reaction process. The schematic illustration of the process for isolating $\mathrm{Eu}^{2+}$ ions in zeolite matrix is depicted in

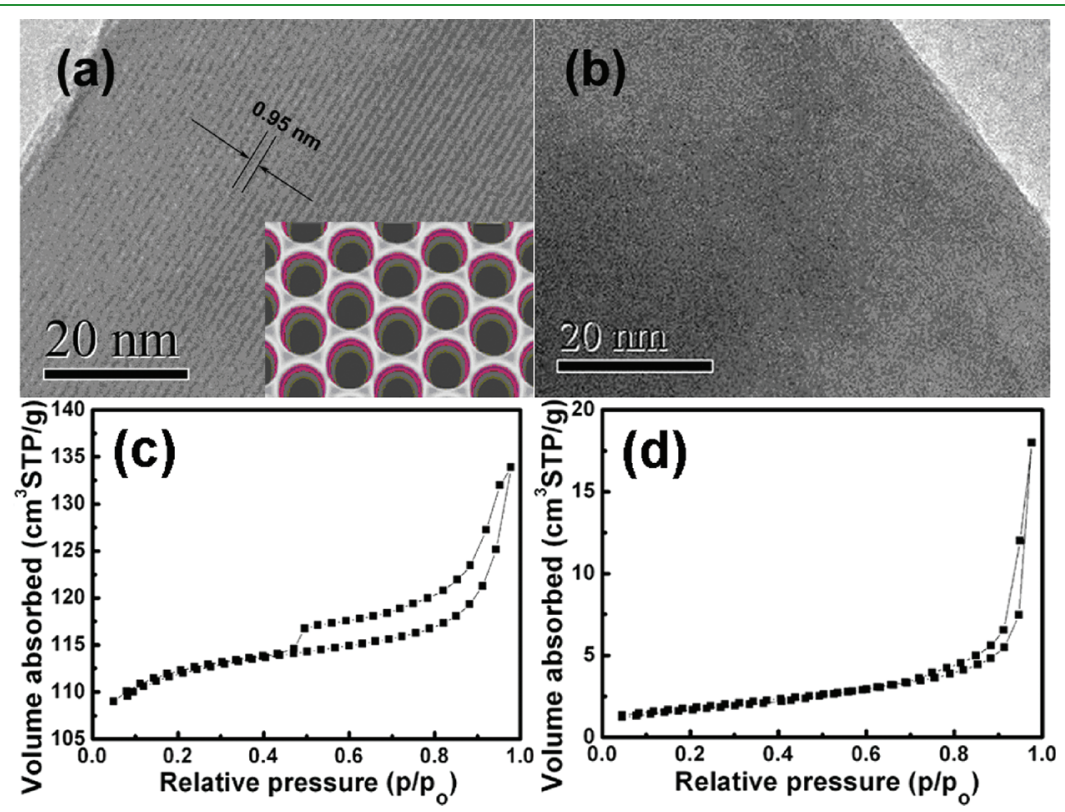

Figure 3. TEM images of (a) pure zeolite $13 \mathrm{X}$, (b) Eu-incorporated zeolite $13 \mathrm{X}$ annealed at $800{ }^{\circ} \mathrm{C}$ in $\mathrm{H}_{2} / \mathrm{N}_{2}$ ambient. Nitrogen adsorption isotherms of (c) pure zeolite and (d) Eu-incorporated zeolite annealed at $800{ }^{\circ} \mathrm{C}$ in $\mathrm{H}_{2} / \mathrm{N}_{2}$ ambient. The inset in a illustrates the micropores of zeolite. 


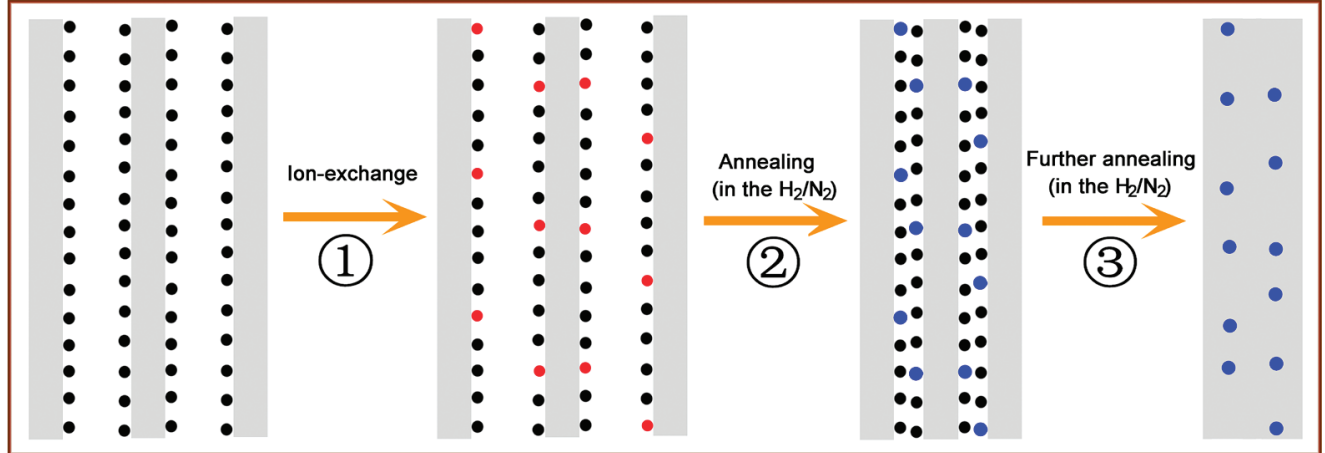

Modeled micropore of zeolite: Sodium ions: $P$ Europium (III) ions: Europium (II) ions:

Figure 4. Schematic illustration of the process for $\mathrm{Eu}^{2+}$ ions isolated by micropores of zeolite.

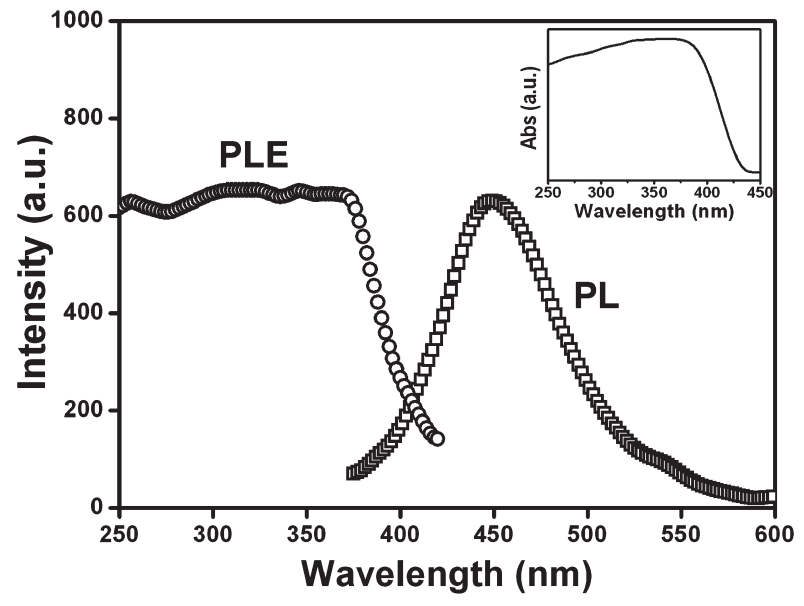

Figure 5. Photoluminescence and photoluminescence excitation spectra of $\mathrm{Eu}^{2+}$-doped zeolite derivatives annealed at $800{ }^{\circ} \mathrm{C}$ in $\mathrm{H}_{2} / \mathrm{N}_{2}$ ambient. The corresponding absorption spectrum is shown as the inset.

Figure 4. First, europium (III) ions substitute the sites of sodium ions by ion-exchange process. At this stage, sodium ions are partially substituted by sodium ions. In our case, the ion exchange rate is less than $20 \%$ (the reaction time is above $12 \mathrm{~h}$ ), ensuring a saturated exchange. Then, the $\mathrm{Eu}^{3+}$ ions are reduced to $\mathrm{Eu}^{2+}$ ions by annealing under a reducing atmosphere and the framework of zeolite shrinks slightly. As the annealing temperature is further increased, the framework of zeolite collapses results in a smaller size with an almost unchanged morphology (see Figure S4 in the Supporting Information). In this process, the $\mathrm{Eu}^{2+}$ ions will be isolated to a large extent in amorphous zeolite derivatives with minimum agglomeration (the sodium ions in the last diagram are ignored).

The photoluminescence spectrum of the as-prepared $\mathrm{Eu}^{2+}$. doped zeolite derivative annealed at $800{ }^{\circ} \mathrm{C}$ was measured at room temperature (Figure 5). The corresponding photoluminescence excitation (PLE) spectrum, monitored at $450 \mathrm{~nm}$, shows a broad excitation range $(250-420 \mathrm{~nm})$. From the PL spectrum, a strong blue emission band centered at $450 \mathrm{~nm}$ can be observed (by $380 \mathrm{~nm}$ excitation), which can be well assigned to $\mathrm{Eu}^{2+}$ emission arising from transitions of the $4 \mathrm{f}^{6} 5 \mathrm{~d}^{1}$ configuration to the ${ }^{8} \mathrm{~S}_{7 / 2}$ level of the $4 \mathrm{f}^{7}$ configuration. However, its excitation is significantly broadened compared to the conventional aluminosilicate materials, ${ }^{13-15}$ which is
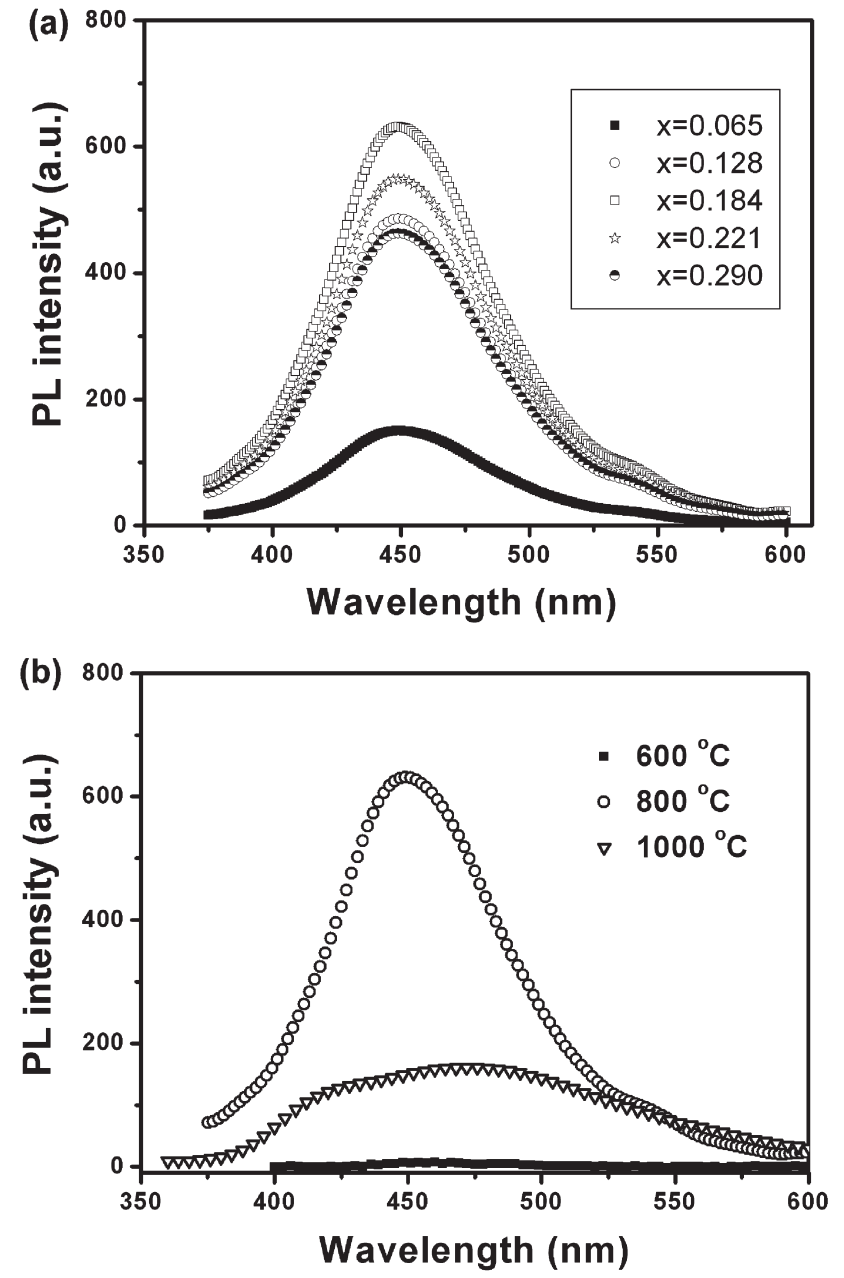

Figure 6. (a) $\mathrm{PL}$ intensity variation of the $\mathrm{Na}_{2-x} \mathrm{Eu}_{x} \mathrm{O} \cdot \mathrm{Al}_{2} \mathrm{O}_{3} \cdot 2.8 \mathrm{SiO}_{2}$ as a function of $\mathrm{Eu}(\mathrm{II})$ composition $(x)$, and (b) PL intensity of samples annealed at temperatures. The spectra were obtained by $380 \mathrm{~nm}$ excitation.

caused by the split of $5 \mathrm{~d}$ orbitals of $\mathrm{Eu}^{2+} \cdot{ }^{44}$ The absorption spectrum of as-prepared $\mathrm{Eu}^{2+}$-doped zeolite derivative is presented as the inset in Figure 5, which is in good agreement with its excitation spectrum. 


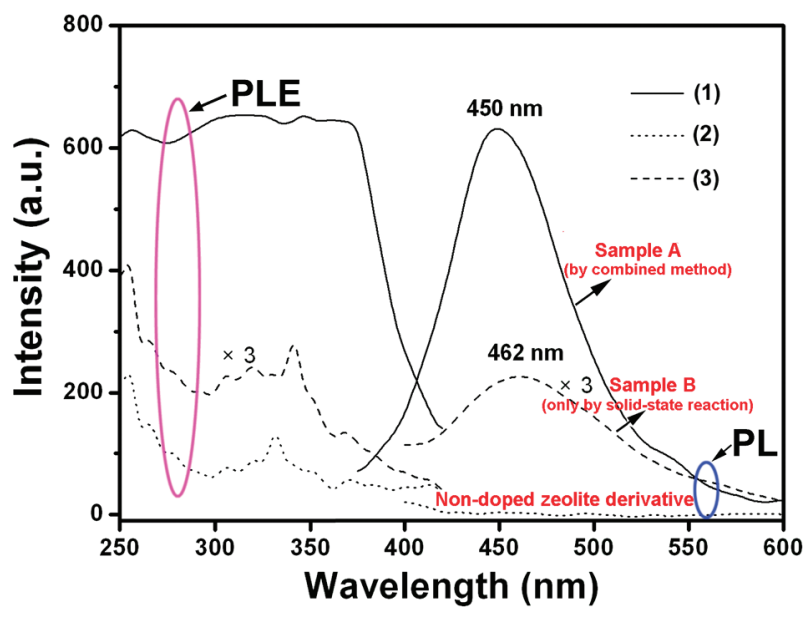

Figure 7. PL and PLE spectra of (1) $\mathrm{Eu}^{3+}$-incorporated zeolite, (2) pure zeolite and (3) mixture of $\mathrm{Eu}_{2} \mathrm{O}_{3}$ and zeolite (7.36 wt $\% \mathrm{Eu}_{2} \mathrm{O}_{3}$ ). All samples were annealed at $800{ }^{\circ} \mathrm{C}$ in $\mathrm{N}_{2} / \mathrm{H}_{2}$.

The PL intensity variation for the samples with different $\mathrm{Eu}^{2+}$ compositions ( $\mathrm{x}$ in $\mathrm{Na}_{2-\mathrm{x}} \mathrm{Eu}_{x} \mathrm{O}$ ) is compared in Figure 6a. It can be seen that the PL intensity reaches the maximum when $\mathrm{x}=0.184$ and the corresponding concentration of $\mathrm{Eu}^{2+}$ in the sample is $9.2 \%$ as measured by inductively coupled plasma optical emission spectrometry (ICP). It is worth mentioning that this $\mathrm{Eu}^{2+}$ concentration here is much higher than that in aluminosilicates reported by previous studies. ${ }^{13-15,45}$ Owing to the special pore structure of zeolites, agglomeration of $\mathrm{Eu}^{2+}$ ions is limited. The concentration quenching effect is mainly caused by the energy transfer among adjacent $\mathrm{Eu}^{2+}$ ions, ${ }^{46,47}$ which can be greatly alleviated by the zeolite spacer, and hence more $\mathrm{Eu}^{2+}$ activator ions can be introduced, leading to more effective doping of $\mathrm{Eu}^{2+}$ in zeolite.

In contrast, the PL emission spectra of zeolites annealed at $600{ }^{\circ} \mathrm{C}$ and at $1000{ }^{\circ} \mathrm{C}$ are quite different (Figure 6b). The PL emission is very weak for the $600{ }^{\circ} \mathrm{C}$ annealed sample. While the emission spectrum consists of two wide bands for the $1000{ }^{\circ} \mathrm{C}$ annealed sample, which is caused by the existence of different available sites for the emission centers in the host lattice. ${ }^{45}$ Compared to Eu-incorporated zeolites annealed at $1000{ }^{\circ} \mathrm{C}$, the PL emission intensity of the $800^{\circ} \mathrm{C}$ annealed sample is more than three times stronger. The strong emission from the $800{ }^{\circ} \mathrm{C}$ annealed sample can be ascribed to the collapse of zeolite framework and the formation of zeolite aluminosilicate derivative while maintaining the inter spacing between adjacent $\mathrm{Eu}^{2+}$ ions. It can be concluded that the microenvironment of $\mathrm{Eu}^{2+}$ sealed in micropores of collapsed zeolite changes significantly at $800{ }^{\circ} \mathrm{C}$. This can be well demonstrated by a parallel experiment of $\mathrm{Eu}^{3+}$. doped zeolite annealed at $800{ }^{\circ} \mathrm{C}$ as $\mathrm{Eu}^{3+}$ emission is particularly sensitive to matrix microenvironment. ${ }^{48}$ The PL spectra of $\mathrm{Eu}^{3+}$ doped zeolite appeared obvious variety when the annealing temperature was up to $800{ }^{\circ} \mathrm{C}$ : broadened emission line width, changed ratio of transition emission, and enhanced emission intensity, indicating the zeolite microenvironment occur significant changes clearly after framework collapse (see Figure S5 in the Supporting Information). It has been reported that the rigid inorganic framework can protect dopants in the matrix and improve the stability of the active centers. ${ }^{2}$ For our present case, the zeolite framework collapsed when the annealing temperature was up to $800{ }^{\circ} \mathrm{C}$, but the $\mathrm{Eu}^{2+}$ ions were sealed/stabilized and well-dispersed in the micropores of zeolites, which promotes effective energy transfer between zeolite matrix and $\mathrm{Eu}^{2+}$ ions leading to the drastic enhancement of PL emission. The Euincorporated zeolites annealed at $1000{ }^{\circ} \mathrm{C}$ form the new phase of $\mathrm{NaAlSiO}_{4}$ and give birth to the agglomeration of $\mathrm{Eu}^{2+}$ ions, causing a decrease of PL emission intensity.

The PL properties of as-prepared $\mathrm{Eu}^{2+}$-doped zeolite derivative annealed at $800{ }^{\circ} \mathrm{C}$ (denoted sample A) were also investigated by comparing nondoped zeolite derivative and $\mathrm{Eu}^{2+}$-doped zeolite derivative prepared by conventional solid-state reaction method without ion exchange process (denoted sample $\mathrm{B}$, the chemical component is in accordance with sample A). All samples were annealed with the same condition (Figure 7). It can be seen that there is no visible light emission from the nondoped zeolite derivative sample. Blue emission can be observed for both sample A and sample B. However, the PL spectrum of sample A is obviously different from sample $B$ prepared by conventional solid method. For the sample $A$, the excitation wavelength range is significantly broadened and the emission peak is blue-shifted. The difference in their spectra is due to the outermost $5 \mathrm{~d}$ orbit involved in the $4 \mathrm{f}^{6} 5 \mathrm{~d}^{1} \rightarrow 4 \mathrm{f}^{7}$ transition of $\mathrm{Eu}^{2+}$, which is very sensitive to the local crystal-field. By conventional mixing method, the $\mathrm{Eu}^{2+}$ ions are difficult to incorporate into micropores of zeolites (for this case, the $\mathrm{Eu}^{2+}$-doped zeolite derivatives only are equivalent to general $\mathrm{Eu}^{2+}$ doped aluminosilicates). Through the combination of ion exchange and solid state reaction, $\mathrm{Eu}^{2+}$ can be incorporated effectively into the micropore structure of zeolite, preventing agglomeration of luminescence ions and prohibiting concentration quenching to the largest extent. As we can see from Figure 7, the as-prepared europium (II)-doped zeolite derivative (absolute quantum yield = $52.6 \%$ ) shows an approximately 9-fold enhancement in blue emission compared to that of the general europium (II)-doped aluminosilicate (absolute quantum yield $=6.2 \%$ ) obtained by conventional solid-state reaction method.

\section{CONCLUSIONS}

In conclusions, the $\mathrm{Eu}$ (II)-doped zeolite derivatives with strong blue emission have been successfully prepared by an ion-exchange and solid-state reaction method. The PL intensity of as-obtained $\mathrm{Eu}^{2+}$-doped zeolite derivatives were the strongest for samples with an amorphous structure annealed at $800^{\circ} \mathrm{C}$. Avoiding excessive agglomeration of luminescence centers through isolating $\mathrm{Eu}^{2+}$ ions in the micropores of zeolite derivative is the reason behind the luminescence enhancement. The strong blue emission and large UV excitation band signify a great promise for phosphor applications. In addition, our method demonstrated here provides a ubiquitous strategy for designing highly luminescent materials. The host material can also be optimized to tune the inter dopant spacing to maximize the dopant concentration while keeping the concentration quenching low.

\section{ASSOCIATED CONTENT}

S Supporting Information. Experimental details on synthesis of isolated europium (II)-doped zeolite derivatives and additional PL, XPS, and SEM analysis. This material is available free of charge via the Internet at http://pubs.acs.org.

\section{AUTHOR INFORMATION}

\section{Corresponding Author}

*E-mail: xibinyu@shnu.edu.cn (X.Y.); hvdemir@ntu.edu.sg (H.V.D.); EXWSun@ntu.edu.sg (X.W.S.). 


\section{ACKNOWLEDGMENT}

The authors thank Science and Technology Development Fund (Shanghai, 09520500500 and $0752 \mathrm{~nm} 008$ ), Scientific Innovation Fund of the Shanghai Education Commission (09ZZ136) and Key Laboratory of Resource Chemistry of Ministry of Education of China for supporting the research. H. V D. and X.Y.Y. also acknowledge generous support from Singapore NRF-RF-2009-09.

\section{REFERENCES}

(1) An, J.; Shade, C. M.; Chengelis-Czegan, D. A.; Petoud, S.; Rosi, N. L J. Am. Chem. Soc. 2011, 133, 1220-1223.

(2) Wang, W. N.; Iskandar, F.; Okuyama, K.; Shinomiya, Y. Adv. Mater. 2008, 20, 3422-3426.

(3) Ziegler, J.; Xu, S.; Kucur, E.; Meister, F.; Batentschuk, M.; Gindele, F.; Nann, T. Adv. Mater. 2008, 20, 4068-4073.

(4) Munro, A. M.; Ginger, D. S. Nano Lett. 2008, 8, 2585-2590.

(5) Achermann, M.; Petruska, M. A.; Koleske, D. D.; Crawford, M. H.; Klimov, V. I. Nano Lett. 2006, 6, 1396-1400.

(6) Zhao, D.; Seo, S. J.; Bae, B. S. Adv. Mater. 2007, 19, 3473-3479.

(7) Park, S.; Vogt, T. J. Am. Chem. Soc. 2010, 132, 4516-4517.

(8) W, B.; Brinkley, S.; Hu, J.; Mikhailovsky, A.; DenBaars, S. P.; Seshadri, R. Chem. Mater. 2010, 22, 2842-2849.

(9) Zhou, S. F.; Jiang, N.; Zhu, B; Yang, H. C.; Ye, S.; Lakshminarayana, G.; Hao, J.; Qiu, J. R. Adv. Funct. Mater. 2008, 18, 1407-1413.

(10) Jang, H. S.; Yang, H.; Kim, S. W.; Han, J. Y.; Lee, S. G.; Jeon, D. Y. Adv. Mater. 2008, 9999, 1-7.

(11) Bachmann, V.; Ronda, C.; Meijerink, A. Chem. Mater. 2009, 21, 2077-2084.

(12) Im, W. B.; Fellows, N. N.; DenBaars, S. P.; Seshadri, R.; Kim, Y. Chem. Mater. 2009, 21, 2957-2966.

(13) Yang, W. J.; Luo, L. Y.; Chen, T. M.; Wang, N. S. Chem. Mater. 2005, 17, 3883-3888.

(14) Zhang, J. Y.; Zhang, Z. T.; Tang, Z. L.; Tao, Y.; Long, X. Chem. Mater. 2002, 14, 3005-3008.

(15) Guo, Y.Z.; Yu, X. B.; Liu, J.; Yang, X. Y. J. Rare Earth 2010, 28, 34-36.

(16) Ortalan, V.; Uzun, A.; Gates, B. C.; Browning, N. D. Nat. Nanotechnol. 2010, 5, 506-510.

(17) Zhang, J. P.; Zhu, A. X.; Lin, R.; B.; Qi, X. L.; Chen, X. M. Adv. Mater. 2011, 23, 1268-1271.

(18) Sun, H. T.; Hosokawa, A.; Miwa, Y. J.; Shimaoka, F.; Fujii, M.; Mizuhata, M.; Hayashi, S.; Deki, S. Adv. Mater. 2009, 21, 3694-3698.

(19) Vohra, V.; Devaux, A.; Dieu, L. Q.; Scavia, G.; Catellani, M.; Calzaferri, G.; Botta, C. Adv. Mater. 2009, 21, 1146-1150.

(20) Busby, M.; Kerschbaumer, H.; Calzaferri, G.; Cola, L. D. Adv. Mater. 2008, 20, 1614-1618.

(21) Mech, A.; Monguzzi, A.; Meinardi, F.; Mezyk, J.; Macchi, G.; Tubino, R. J. Am. Chem. Soc. 2010, 132, 4574-4576.

(22) Lezhnina, M.; Laeri, F.; Benmouhadi, L.; Kynast, U. Adv. Mater. 2006, 18, 280-283.

(23) Wada, Y.; Sato, M.; Tsukahara, Y. Angew. Chem., Int. Ed. 2006, 45, 1925-1928.

(24) Zhang, H. H.; Li, H. R. J. Mater. Chem. 2011, 21, 13576-13580.

(25) Bai, Z. H.; Sun, H. T.; Fujii, M.; Miwa, Y.; Hasegawa, T.; Mizuhata, M.; Hayashi, S. J. Phys. D: Appl. Phys. 2011, 44, 155101-155105.

(26) Bai, Z. H.; Sun, H. T.; Hasegawa, T.; Fujii, M.; Shimaoka, F.; Miwa, Y.; Mizuhata, M.; Hayashi, S. Opt. Lett. 2010, 35, 1926-1928.

(27) Tiseanu, C.; Kumke, M. U.; Parvulescu, V. I.; Gessner, A.; Gagea, B.; Martens, J. J. Phys. Chem. B 2008, 112, 10552-10562.

(28) Im, W. B.; George, N.; Kurzman, J.; Brinkley, S.; Mikhailovsky, A.; Hu, J.; Chmelka, B. F.; DenBaars, S. P.; Seshadri, R. Adv. Mater. 2011, 23, 2300-2305.

(29) Petrykin, V.; Okube, M.; Yamane, H.; Sasaki, S.; Kakihana., M. Chem. Mater. 2010, 22, 5800-5802.

(30) Yang, X. Y.; Liu, J.; Yang, H.; Yu, X. B.; Guo, Y. Z.; Zhou, Y. Q.; Liu, J. Y. J. Mater. Chem. 2009, 19, 3771-3774.
(31) Sohn, K. S.; Park, D. H.; Cho, S. H.; Kwak, J. S.; Kim, J. S. Chem. Mater. 2006, 18, 1768-1772.

(32) Wickleder, C.; Zhang, S.; Anorg., Z. Allg. Chem 2008, 2088.

(33) Zhang, S. Y.; Nakai, Y.; Tsuboi, T.; Huang, Y. L.; Seo, H. J. Chem. Mater. 2011, 23, 1216-1224.

(34) Huang, C. H.; Liu, W. R.; Chen, T. M. J. Phys. Chem. C 2010, 114, 18698-18710.

(35) Wu, Y. C.; Wang, D. Y.; Chen, T. M.; Lee, C. S.; Chen, K. J.; Kuo, H. C. ACS Appl. Mater. Interfaces 2011, 3, 3195-3199.

(36) Kwon, K. H.; Im, W. B.; Jang, H. S.; Yoo, H. S.; Jeon, D. Y. Inorg. Chem. 2009, 48, 11525-11532.

(37) Zhao, X. X.; Wang, X. J.; Chen, B. J.; Meng, Q. Y.; Yan, B.; Di, W. H. Opt. Mater. 2007, 29, 1680-1684.

(38) Bünzli, J. C. Nat. Chem. 2010, 2, 696.

(39) Hecht, C.; Stadler, F.; Schmidt, P. J.; Günne, J. S.; Baumann, V.; Schnick, W. Chem. Mater. 2009, 21, 1595-1601.

(40) Piao, X. Q.; Horikawa, T.; Hanzawa, H; Machida, K. I. Appl. Phys. Lett. 2006, 88, 161908-161913.

(41) Wu, H. E.; Yang, X. Y.; Yu, X. B.; Liu, J.; Yang, H.; Lv, H. B.; Yin, K. Z. J. Alloys Compd. 2009, 480, 867-869.

(42) Fang, Y.; Li, H. R.; Wang, Y.; Liu, X. W. Dalton Trans. 2010, 39, 11594-11598.

(43) Shiralkar, V. P.; Kulkarni, S. B. J. Therm. Anal. Calorim. 1982, 25, 399-407.

(44) Piao, X. Q.; Machida, K. I.; Horikawa, T.; Hanzawa, H.; Shimomura, Y.; Kijima, N. Chem. Mater. 2007, 19, 4592-4599.

(45) Denis, G.; Deniard, P.; Gautron, E.; Clabau, F.; Garcia, A.; Jobic, S. Inorg. Chem. 2008, 47, 4226-4235.

(46) Li, Y. Q.; Hirosaki, N.; Xie, R. J.; Takeda, T.; Mitomo, M. Chem. Mater. 2008, 20, 6704-6714.

(47) Xie, R. J.; Hirosaki, N.; Mitomo, M.; Yamamoto, Y.; Suehiro, T. J. Phys. Chem. B 2004, 108, 12027-12031.

(48) Huang, J. M.; Bekiari, V.; Lianos, P. Prog. Colloid Polym. Sci. 2001, 118, 27-29. 